\title{
Overlapping of Sturge-Weber Syndrome and Klippel-Trenaunay Weber Syndrome With Upper Limb Involvement
}

\author{
Hossein Ali Ebrahimi, ${ }^{1, *}$ and Saeed Ebrahimi ${ }^{2}$ \\ ${ }^{1}$ Neurology Research Center, Kerman University of Medical Sciences, Kerman, IR Iran \\ ${ }^{2}$ General Physician, Faculty of Medicine, Tehran University of Medical Sciences, Tehran, IR Iran \\ "Corresponding author: Hossein Ali Ebrahimi, Neurology Research Center, Kerman University of Medical Sciences, Kerman, IR Iran. E-mail: hebrahimi@kmu.ac.ir
}

Received 2015 February 26; Accepted 2015 June 3.

\begin{abstract}
Introduction: The phakomatoses are a group of clinical disorders that are linked. Overlap between Sturge-Weber syndrome (SWS) and Klippel-Trenaunay Weber syndrome (KTWS) is very rarely. We presented a case of SWS with KTWS that involved upper limb. Case Presentation: A24-year-old male with extensive port-wine staining over left side of his face, extending to lower eyelids, cheeks, neck and left upper extremity. The size of mid arm circle in left side was $34 \mathrm{~cm}$ and in right side was $27 \mathrm{~cm}$.

Conclusions: This is a case of overlap SWS and KTWS that involved upper limb.
\end{abstract}

Keywords: Sturge Weber Syndrome, Klippel-Trenaunay Weber Syndrome, Upper Limb

\section{Introduction}

The phakomatoses are a group of clinical disorders that are linked. One of these disorders is Sturge-Weber syndrome(SWS) and the other is Klippel-Trenaunay Weber syndrome (KTWS). The SWS is a neurocutaneus congenital but not an inheried disease and it occurs sporadically. It is a disorder of vasculature which belongs to the group of phakomatosis characterized by nevus flammeus and angiomas of the meninges, abnormal blood vessels on the cerebral cortex [1]. It is a rare disease that occurs with a frequency of approximately 1 per 50,000 [2]. These changes are usually unilateral. It can be seen in both sexes equally. The SWS and port-wine stains are caused by a somatic activating mutation in GNAQ [3].

KTWS is a very rare; the prevalence is $1 / 20,000-40,000$. It is sporadic, complex malformation characterized by the clinical triad of (A) capillary malformations (B) soft tissue and bone hypertrophy and (C) atypical, mostly lateral varicosity [4].

\section{Case Presentation}

A 24-year-old male who referred to our ward due to frequent seizures. The seizure attacks start on left extremities and then may be generalized since three years ago. Physical examination revealed that there was extensive portwine staining over left side of his face, extending to lower eyelids, cheeks, neck and left upper extremity (Figure 1). The port wine stain lesions were after birth. The size of mid arm circle in left side was $34 \mathrm{~cm}$ and in right side was $27 \mathrm{~cm}$, but the episclera and retina were normal (Figure 2). Laboratory exams was normal. Electroencephalogram was abnormal with epileptic discharges that prominent in right hemisphere. Brain MRI was normal. The parents of this patient have not family relation and there is no other patient like this patient in his family.

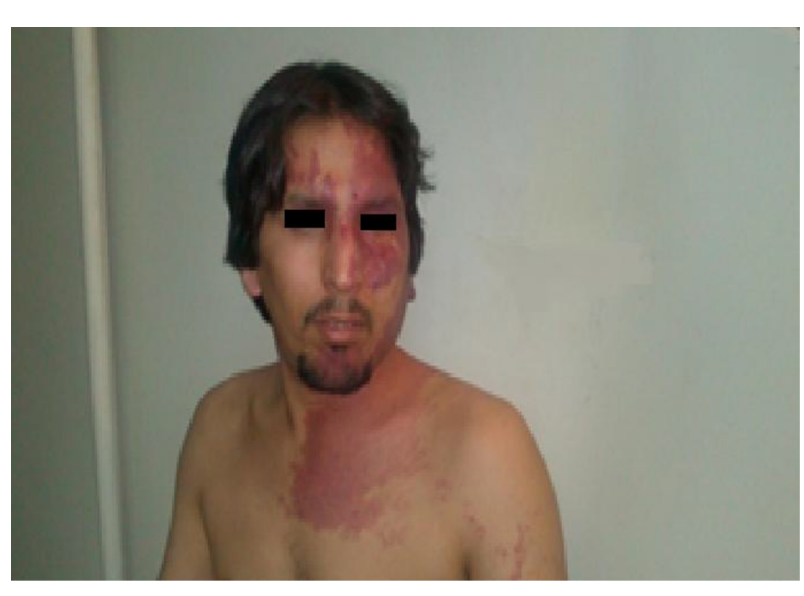

Figure 1. Distribution of Cutaneous Lesions of Face, Neck and Chest in Left Side

\section{Discussion}

Sturge Weber syndrome is three types. Type 1 is the most common form, this type involves both facial and 


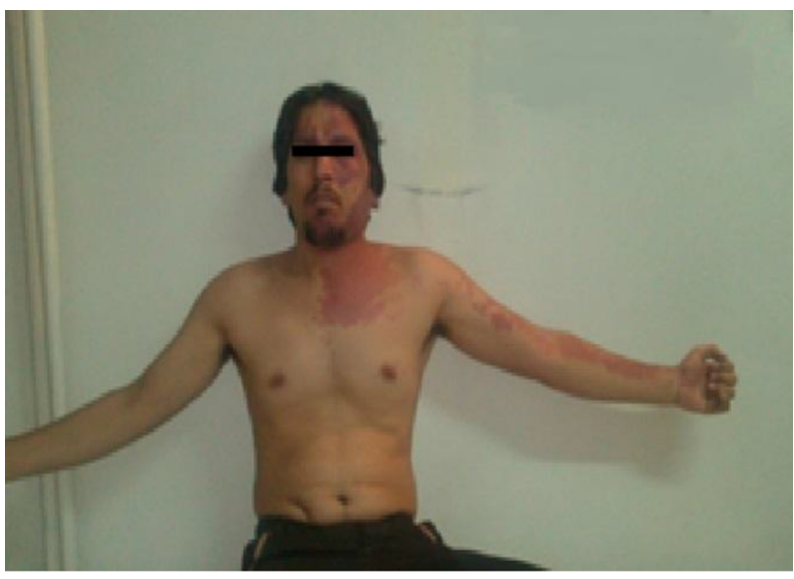

Figure 2. The Left Arm is Larger Than Right

leptomenigeal(brain) angiomas (vascular malformations) and may involve glaucoma. Type 2 involves a facial angioma and the possibility of glaucoma, but no evidence of intracranial disease. Type 3 is commonly noted to have a leptomeningeal angioma [5]. Our patient has typical lesions on 1, 2 and 3th division of 5th nerve on left side, and even neck in left side (Figure 1), but the MRI was normal. The lesions are usually found only in one extremity, most frequently, lower limb, but in our patient the lesions were located only within the upper extremity(Figure 2), the skin lesions were seen after birth. The patient has normal intelligence. In our patient the seizure attacks started 4 years ago. The seizures were focal, but sometimes be generalized is same other reports [6]. In a study the seizures occurred in $85.5 \%$ of SWS patients [7]. In this patient the size of left (with port wine stains) mid arm circle is more than the right side. Hypertrophy of the limb is observed in $67 \%$ of all the patients with KTWS [8]. The SWS in our patient was type 2 . Several hypotheses regarding cause and pathogenesis in KTS exist, but none explains all KTS characteristics completely.

\section{Footnote}

Authors' Contribution: Hossein Ali Ebrahimi is writer and corresponding author. Saeed Ebrahimi: photographer, translator and history taker.

\section{References}

1. Griffiths PD. Sturge-Weber syndrome revisited: the role of neuroradiology. Neuropediatrics. 1996;27(6):284-94. doi: 10.1055/s-2007-973796. [PubMed: 9050045].

2. Thomas-Sohl KA, Vaslow DF, Maria BL. Sturge-Weber syndrome: a review. Pediatr Neurol. 2004;30(5):303-10. doi: 10.1016/j.pediatrneurol.2003.12.015. [PubMed: 15165630].

3. Shirley MD, Tang H, Gallione CJ, Baugher JD, Frelin LP, Cohen B, et al. Sturge-Weber syndrome and port-wine stains caused by somatic mutation in GNAQ. N Engl J Med. 2013;368(21):1971-9. doi: 10.1056/NEJMoa1213507. [PubMed: 23656586].

4. Gloviczki P, Driscoll DJ. Klippel-Trenaunay syndrome: current management. Phlebology. 2007;22(6):291-8. [PubMed: 18274338].

5. Roach ES. Neurocutaneous syndromes. Pediatr Clin North Am. 1992;39(4):591-620. [PubMed: 1635798].

6. Chaudhary SC, Sonkar SK, Kumar V, Golchha S. Sturge Weber syndrome. J Assoc Physicians India. 2011;59:327-9. [PubMed: 21751615].

7. Pascual-Castroviejo I, Pascual-Pascual SI, Velazquez-Fragua R, Viano J. Sturge-Weber syndrome: study of 55 patients. Can J Neurol Sci. 2008;35(3):301-7. [PubMed: 18714797].

8. Redondo P, Bastarrika G, Aguado L, Martinez-Cuesta A, Sierra A, Cabrera J, et al. Foot or hand malformations related to deep venous system anomalies of the lower limb in Klippel-Trenaunay syndrome. J Am Acad Dermatol. 2009;61(4):621-8. doi: 10.1016/j.jaad.2009.04.027. [PubMed: 19577333]. 